\title{
Maternal infectious diseases, antimicrobial therapy or immunizations: Very few contraindications to breastfeeding
}

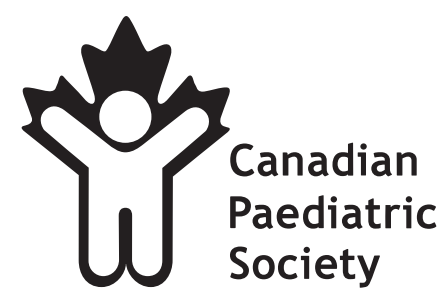

$\mathrm{T}_{\mathrm{b}}^{\mathrm{h}}$ he Canadian Paediatric Society recommends exclusive breastfeeding as the optimal method of infant feeding for the first six months of life for healthy, term infants (1). There are many benefits associated with breastfeeding, including nutritional, immunological, psychological, developmental, environmental, social, economic and health (eg, decrease in infectious diseases) (2-4). To promote, protect and support breastfeeding, every effort must be made to minimize contraindications to breastfeeding, particularly unnecessary ones. The present article summarizes the maternal infectious diseases in which continuing breastfeeding is recommended, the very few infectious diseases in which it is not recommended, the rare instances in which maternal antimicrobial therapy indicates a caution for breastfeeding, and the continuation of breastfeeding when a mother or her infant is receiving a routine recommended immunization.

\section{MATERNAL INFECTIOUS DISEASES AND BREASTFEEDING}

Human breast milk is not sterile; it frequently contains organisms found in the mother's microbial skin flora (5). Normal healthy breastfeeding infants become colonized with their mother's flora over time (6). While breast milk can be a source of maternally derived commensal and pathogenic microorganisms, there are very few maternal infectious diseases for which cessation or interruption of breastfeeding is indicated (2,7-9).

When a nursing mother presents with symptoms of an infectious disease, she has already exposed her infant to the pathogen. Cessation of breastfeeding does not prevent exposure, and may instead decrease the infant's protection that comes through specific maternal antibodies and other protective factors found in human milk. Therefore, common maternal bacterial, fungal and viral infections in which the mother's health is not compromised are not contraindications to breastfeeding (Table 1).

Maternal bacterial infections are rarely complicated by transmission to the infant through breastfeeding. Mothers with mastitis or breast abscesses should be encouraged to continue breastfeeding $(5,7,9)$. In instances of breast abscess where pain interferes with breastfeeding, the infant can continue to breastfeed on the nonabscessed breast. Similarly, maternal tuberculosis (TB) is compatible with breastfeeding, provided the mother is not contagious or she has received two weeks of appropriate TB treatment (7-9). Continuing breastfeeding while on TB therapy is not a problem, as these drugs appear to be safe for use with breastfeeding $(8,10,11)$. Breastfed neonates of women on isoniazid therapy should receive a multivitamin supplement, including pyridoxine (12). If both mother and infant are taking isoniazid, then there are concerns about possible excessive drug concentration in the infant (12). Consultation with an expert is indicated.

With parasitic infections such as malaria, breastfeeding should be continued provided the mother's clinical condition allows for it. While the antimalarials chloroquine, hydroxychloroquine and quinine are found in variable quantities in breast milk, all three are regarded as compatible with breastfeeding (10) unless the infant has glucose6-phosphate dehydrogenase (G6PD) deficiency, in which case withdrawal of quinine is advised (11). Similarly, primaquine should not be used unless both the mother and infant have normal G6PD levels. Precautions to minimize insect-borne infections should be encouraged. Insect repellents help to reduce mosquito bites, which may transmit malaria or viruses such as West Nile. There are no reported adverse events following use of repellents containing diethyltoluamide or picaridin in breastfeeding mothers (13).

While maternal fungal infections such as candidal vaginitis can lead to infant colonization, this is not a contraindication to breastfeeding, nor is maternal treatment with topical or systemic antifungal agents such as fluconazole $(8,11)$.

For most maternal viral infections, ongoing breastfeeding is recommended with few exceptions (Table 1) $(7,8)$. With maternal HIV infection, in resource-rich settings such as Canada, where a safe and culturally accepted replacement is available, breastfeeding is not recommended because HIV transmission to the infant has been well documented (8,9,14-16). Emotional support for the mother to not breastfeed may be required; in some instances, financial support for formula purchase may be necessary as well. In more resource-limited settings, the optimal feeding method for infants whose mothers are HIV positive is still unclear (16). Breastfeeding is also not advised for mothers 
TABLE 1

Selected maternal infections and corresponding breastfeeding management for healthy term infants

\begin{tabular}{|c|c|c|}
\hline Maternal infection/disease & Microbial agent(s) & Breastfeeding recommendation \\
\hline \multicolumn{3}{|l|}{ Bacteria } \\
\hline Mastitis and breast abscesses & $\begin{array}{l}\text { Staphylococcus aureus } \\
\text { Streptococcus species } \\
\text { Gram negatives: Escherichia coli } \\
\text { Rarely: Salmonella species, } \\
\text { mycobacteria, candida, Cryptococcus }\end{array}$ & $\begin{array}{l}\text { Continue breastfeeding unless there is obvious pus, in which } \\
\text { case pump and discard from the infected breast and continue } \\
\text { breastfeeding with the other breast }\end{array}$ \\
\hline TB & Mycobacterium tuberculosis & $\begin{array}{l}\text { Main route of transmission is airborne. With active TB, delay } \\
\text { breastfeeding until mother has received } 2 \text { weeks of } \\
\text { appropriate anti-TB therapy; provide TB prophylaxis for infant }\end{array}$ \\
\hline Urinary tract infection & Gram negatives: $E$ coli, etc & Continue breastfeeding \\
\hline $\begin{array}{l}\text { Bacterial infection abdominal wall } \\
\text { postcesarean section }\end{array}$ & Skin microbes & Continue breastfeeding \\
\hline Diarrhea & Salmonella, Shigella, E coli, Campylobacter & Continue breastfeeding; good hand hygiene \\
\hline $\begin{array}{l}\text { Other bacterial infections in which } \\
\text { the mother's physical condition and } \\
\text { general health is not compromised }\end{array}$ & Wide range of bacterial microbes & Continue breastfeeding \\
\hline \multicolumn{3}{|l|}{ Fungi } \\
\hline Candidal vaginitis & Candida & Continue breastfeeding; good hand hygiene \\
\hline \multicolumn{3}{|l|}{ Viruses } \\
\hline & Cytomegalovirus & Continue breastfeeding \\
\hline \multirow[t]{3}{*}{ Hepatitis } & Hepatitis A virus & $\begin{array}{l}\text { Continue breastfeeding; immunoglobulin prophylaxis for the } \\
\text { infant; good hand hygiene }\end{array}$ \\
\hline & HBV & $\begin{array}{l}\text { Continue breastfeeding; routine prevention of infant } \mathrm{HBV} \\
\text { infection with HBIG at birth; immunization with } \mathrm{HBV} \text { vaccine }\end{array}$ \\
\hline & Hepatitis $C$ virus & Continue breastfeeding \\
\hline Herpes & HSV-1, HSV-2 & $\begin{array}{l}\text { Continue breastfeeding; good hand hygiene. If there are lesions } \\
\text { on breasts, interrupt until lesions are healed (crusted) }\end{array}$ \\
\hline \multirow{4}{*}{ Chicken pox, shingles } & HIV & Contraindicated; see text for details \\
\hline & HTLV-1, HTLV-2 & Contraindicated \\
\hline & Parvovirus & Continue breastfeeding \\
\hline & West Nile virus & Continue breastfeeding \\
\hline
\end{tabular}

Data from references 7 to 9 and 12 to 15. HBIG Hepatitis B immune globulin; HBV Hepatitis B virus; HSV Herpes simplex virus; HTLV Human T-Iymphotropic virus; TB Tuberculosis; VZIG Varicella-zoster immune globulin; VZV Varicella-zoster virus

with human T-lymphotropic virus type 1 or 2 infection. $(7,8)$. In mothers with latent cytomegalovirus (CMV) infection, the virus reactivates in breast milk during the postpartum period and can be transmitted to the infant with breastfeeding (9). This does not pose a risk to the term infant because serious disease is prevented by placentally transferred maternal antibody. For premature infants, especially those less than 32 weeks gestation, breastfeeding from a CMV-positive mother is controversial. However, recent studies suggest that that the relative incidence and severity of CMV disease in such premature infants are low, and that the rate of CMV acquisition is not much different from the rate of acquisition in premature infants fed CMV-negative breast milk $(17,18)$, providing further support for fresh breast milk feeding even if the mother is CMV positive (19).

\section{MATERNAL ANTIMICROBIAL THERAPY AND BREASTFEEDING}

There are very few instances in which maternal therapy with commonly used antimicrobial agents precludes continuation of breastfeeding $(8,10,11)$ (Table 2). Even maternal therapy with tetracycline, aminoglycosides or quinolones is not an indication to withhold breastfeeding.

\section{MATERNAL IMMUNIZATION AND BREASTFEEDING}

Breastfeeding is not a contraindication to the administration of routine recommended vaccines to the infant or the mother (20).

ACKNOWLEDGEMENT: This document was reviewed by the Canadian Paediatric Society Drug Therapy and Hazardous Substances Committee. 


\section{TABLE 2}

Selected maternal antimicrobial therapies and corresponding breastfeeding management for healthy term infants

Maternal antimicrobial therapy
Antibiotics
Group 1: Penicillins, cephalosporins, carbapenams, macrolides,
aminoglycosides, quinolones
Group 2: High-dose metronidazole
Group 3: Chloramphenicol
Group 4: Trimethoprim/sulfamethoxazole, sulfisoxazole, dapsone

\section{Antitubercular drugs}

Isoniazid, rifampin, streptomycin, ethambutol

\author{
Antiparasitics \\ Group 1: Chloroquine, quinidine, ivermectin; \\ maternal topical diethyltoluamide or picaridin \\ Group 2: Primaquine, quinine
}

\section{Antifungals}

Fluconazole, ketoconazole

Antivirals

Acyclovir, valacyclovir, amantadine

\section{Breastfeeding recommendation}

Continue breastfeeding

Discontinue breastfeeding for $12 \mathrm{~h}$ to $24 \mathrm{~h}$ to allow excretion of dose

Caution: Possible idiosyncratic bone marrow suppression

Proceed with caution if nursing infant has jaundice or G6PD deficiency, and also if ill, stressed or premature

Continue breastfeeding. While mother is taking isoniazid, administer pyridoxine for the nursing infant

Continue breastfeeding

Contraindicated during breastfeeding unless both mother and baby have normal G6PD levels

Continue breastfeeding

Continue breastfeeding. If considering prolonged use of amantadine,

observe for milk suppression, as it can suppress prolactin production

Data from references 8,10,11 and 13. G6PD Glucose-6-phosphate dehydrogenase

\section{REFERENCES}

1. Canadian Paediatric Society, Nutrition Committee. [Principal author: Margaret Boland] Exclusive breastfeeding should continue to six months. Paediatr Child Health 2005;10:148.

2. Gartner LM, Morton J, Lawrence RA, et al; American Academy of Pediatrics Section on Breastfeeding. Breastfeeding and the use of human milk. Pediatrics 2005;115:496-506.

3. Ogundele MO. A viewpoint of mucosal immunity in relation to early feeding method. Intern J Food Sci Tech 2001;36:341-55.

4. Heinig MJ. Host defense benefits of breastfeeding for the infant. Effect of breastfeeding duration and exclusivity. Pediatr Clin North Am 2001;48:105-23.

5. Michie C, Lockie F, Lynn W. The challenge of mastitis. Arch Dis Child 2003;88:818-21.

6. Kawada M, Okuzumi K, Hitomi S, Sugishita C. Transmission of Staphylococcus aureus between healthy, lactating mothers and their infants by breastfeeding. J Hum Lact 2003;19:411-7.

7. American Academy of Pediatrics. Transmission of infectious agents via human milk. In: Pickering LK, ed. Red Book: 2003 Report of the Committee on Infectious Diseases, 26th edn. Illinois: American Academy of Pediatrics, 2003:118-21.

8. Lawrence RM, Lawrence RA. Breast milk and infection. Clin Perinatol 2004:31:501-28

9. Lamounier JA, Moulin ZS, Xavier CC. [Recommendations for breastfeeding during maternal infections]. J Pediatr (Rio J) 2004;80(Suppl):S181-8.

10. American Academy of Pediatrics, Committee on Drugs. The transfer of drugs and other chemicals into breast milk. Pediatrics 2001;108:776-89.

11. Mathew JL. Effect of maternal antibiotics on breast feeding infants. Postgrad Med J 2004;80:196-200.
12. American Academy of Pediatrics. Perinatal Infections. In: Gilstrap LC, Oh W, eds. Guidelines for Perinatal Care, 5th edn. Illinois: American Academy of Pediatrics, 2002:285-329.

13. Centers for Diseases Control and Prevention. Updated Information regarding Insect Repellents < www.cdc.gov/ncidod/dvbid/westnile/ RepellentUpdates.htm> and West Nile Virus, Pregnancy and Breastfeeding < $<$ www.cdc.gov/ncidod/dvbid/westnile/qa/ breastfeeding.htm $>$ (Version current at September 17, 2006).

14. Canadian Paediatric Society, Infectious Diseases and Immunization Committee. [Principal author: Susan King] Evaluation and treatment of the human immunodeficiency virus-1-exposed infant. Paediatr Child Health 2004;9:409-17.

15. Read JS; American Academy of Pediatrics, Committee on Pediatric AIDS. Human milk, breastfeeding, and transmission of human immunodeficiency virus type 1 in the United States. Pediatrics 2003;112:1196-2003.

16. Bulterys M, Fowler MG, Van Rompay KK, Kourtis AP. Prevention of mother-to-child transmission of HIV-1 through breast-feeding: Past, present, and future. J Infect Dis 2004;189:2149-53.

17. Yasuda A, Kimura H, Hayakawa M, et al. Evaluation of cytomegalovirus infections transmitted via breast milk in preterm infants with a realtime polymerase chain reaction assay. Pediatrics 2003;111:1333-6.

18. Miron D, Brosilow S, Felszer K, et al. Incidence and clinical manifestations of breast milk-acquired Cytomegalovirus infection in low birth weight infants. J Perinatol 2005;25:299-303.

19. Schanler RJ. CMV acquisition in premature infants fed human milk: Reason to worry? J Perinatol 2005;25:297-8.

20. Health Canada, National Advisory Committee on Immunization. Canadian Immunization Guide, 6th edn. Ottawa: Health Canada, 2002:19.

\section{INFECTIOUS DISEASES AND IMMUNIZATION COMMITTEE}

Members: Drs Simon Richard Dobson, BC Children's Hospital, Vancouver, British Columbia; Joanne Embree, University of Manitoba, Winnipeg, Manitoba (chair); Joanne Langley, IWK Health Centre, Halifax, Nova Scotia; Dorothy Moore, The Montreal Children's Hospital, Montreal, Quebec; Gary Pekeles, The Montreal Children's Hospital, Montreal, Quebec (board representative); Élisabeth Rousseau-Harsany, Sainte-Justine UHC, Montreal, Quebec (board representative); Lindy Samson, Children's Hospital of Eastern Ontario, Ottawa, Ontario

Consultant: Dr Noni MacDonald, Department of Pediatrics, IWK Health Centre, Halifax, Nova Scotia

Liaisons: Drs Upton Allen, The Hospital for Sick Children, Toronto, Ontario (Canadian Pediatric AIDS Research Group); Scott Halperin, IWK Health Centre, Halifax, Nova Scotia (IMPACT); Monica Naus, BC Centre for Disease Control, Vancouver, British Columbia (Health Canada, National Advisory Committee on Immunization); Larry Pickering, Centers for Disease Control and Prevention, Atlanta, Georgia, USA (American Academy of Pediatrics, Committee on Infectious Diseases)

Principal author: Dr Noni E MacDonald, IWK Health Centre, Halifax, Nova Scotia

The recommendations in this statement do not indicate an exclusive course of treatment or procedure to be followed. Variations, taking into account individual circumstances, may be appropriate. Internet addresses are current at time of publication. This article also appears in the October 2006 issue of Paediatrics Eु Child Health [Paediatr Child Health 2006;11(8):489-491]. 


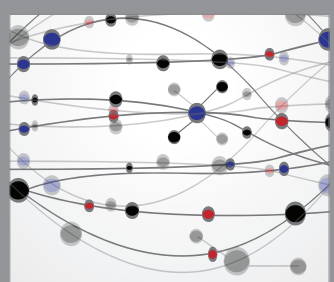

The Scientific World Journal
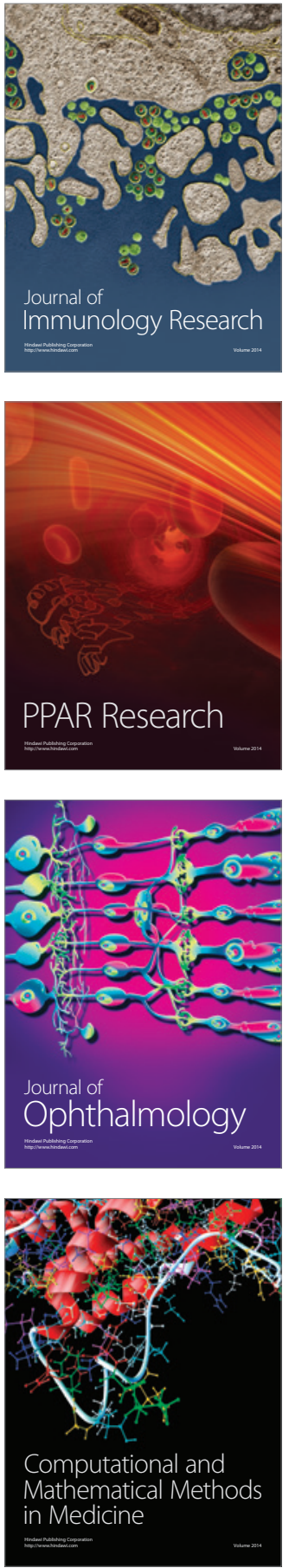

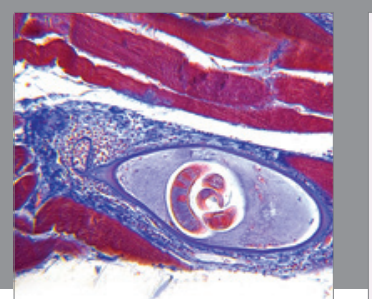

Gastroenterology Research and Practice

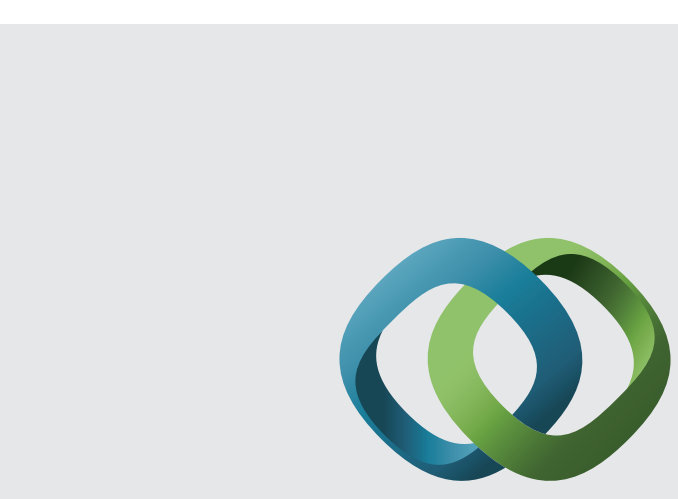

\section{Hindawi}

Submit your manuscripts at

http://www.hindawi.com
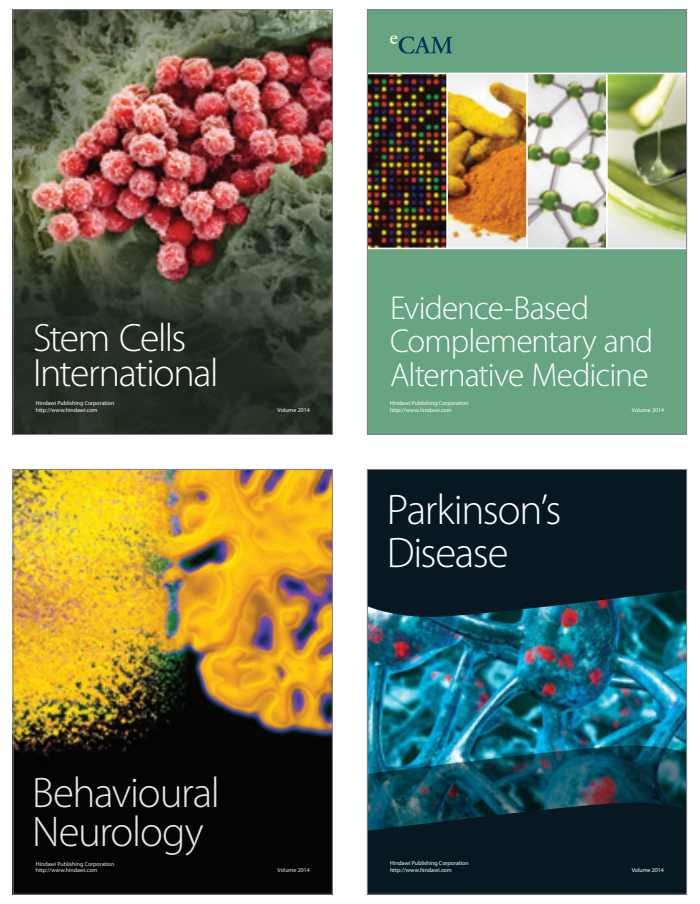
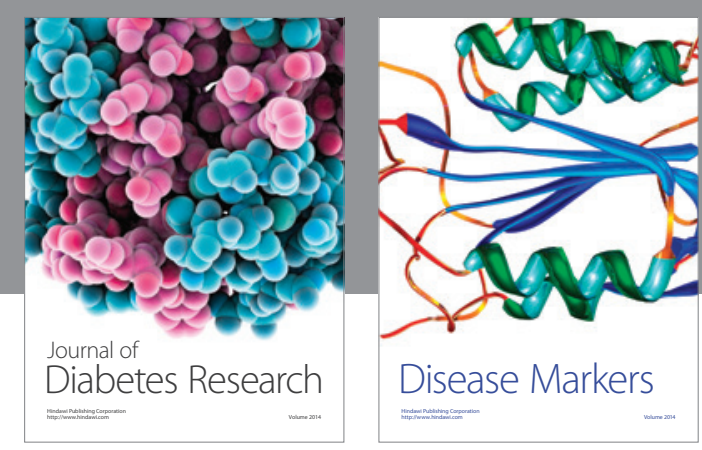

Disease Markers
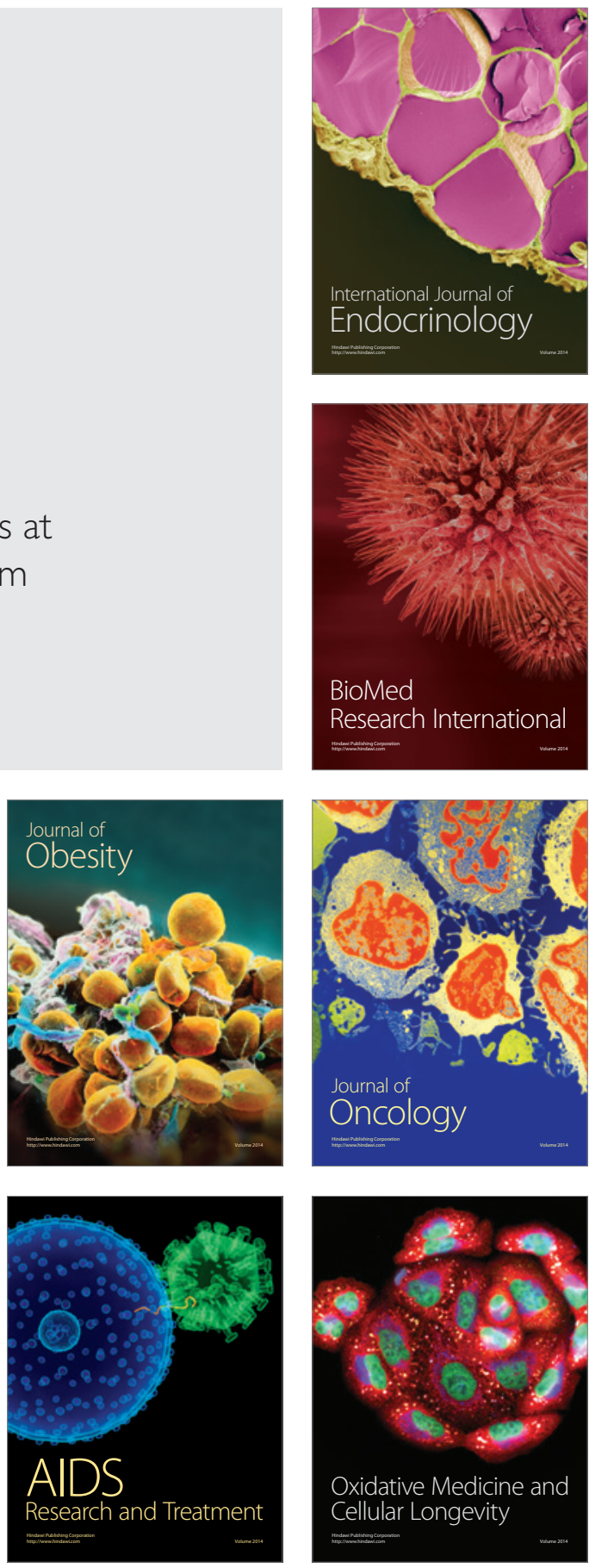